\author{
U.S. Army Research Institute \\ for the Behavioral and Social Sciences
}

Research Report 1632

\title{
Survey of Army Personnel Interested in Teaching
}

\author{
C. Emily Feistritzer \\ National Center for Education Information
}
UNIVERSITY OF VIRGINIA
ALDERMAN LIBRARY

MAR 81994

GOVERNMENT DOCUMENTS

Givg

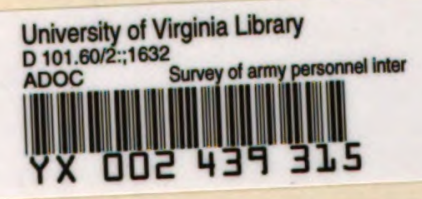

November 1992

Approved for public release; distribution is unlimited. 